\title{
RELEVANSI OPERASIONAL BAHASA DENGAN OTAK MANUSIA
}

\author{
Zulfatun Anisah \\ STAI Al Hikmah Tuban \\ zulfa7664@gmail.com
}

\begin{abstract}
ABSTRAK
Berdasarkan struktur biologis alat suara dan organisasi otak manusia, bahwasanya otak memegang peranan penting dalam bahasa. Proses bahasa dalam otak meliputi dua hal. Apabila informasi yang masuk dalam bentuk lisan, maka bunyi-bunyi ditanggapi di lobe temporal, khususnya pada korteks primer pendengaran. Selanjutnya bunyi-bunyi tersebut akan diolah lalu dikirim ke daerah Wernicke untuk diinterpretasikan. Jika memerlukan adanya tanggapan secara verbal, maka terlebih dahulu interpretasi dikirim ke daerah Broca melalui fasikulus arkuat. Berbeda pada input yang berupa tulisan, masukan ditanggapi langsung oleh korteks visual di lobe osipital. Masukan tadi tidak dikirim langsung ke daerah Wernicke, akan tetapi harus melewati girus anguler. Girus anguler ini yang mengoordinasikan daerah pemahaman dengan daerah osipital. Selain itu, otak memiliki bagian yang menangani fungsi-fungsi intelektual dan bahasa yang dinamakan korteks serebral. Dalam korteks serebral manusia terdapat hemisfir kiri dan hemisfir kanan. Hemisfir kiri bertanggung jawab atas ihwal kebahasaan, Untuk itu jika terjadi gangguan pada hemisfir kiri secara otomatis kemampuan wicara berbahasa orang itu menurun dengan drastis. Hemisfir kanan lebih dominan dalam menangani tugas-tugas yang berkaitan dengan desain dan pola-pola visual. Hemisfir kanan juga memengaruhi kebahasaan seseorang, namun tidak sebesar hemisfir kiri. Jika hemisfir kanannya yang terganggu, maka kemampuan mereka dalam mengurutkan peristiwa sebuah cerita (narasi) menjadi kacau dan mendapatkan kesukaran menarik inferensi.
\end{abstract}

Kata kunci: otak, bahasa, lobe temporal, korteks prier, broca, fasikulus arkuat, dan lobe osipital

\begin{abstract}
Based on the biological structure of the instrument and organization of the human brain, the brain plays an important role in language. The process of language in the brain includes two things. If information is entered in an oral form, the sounds are responded to in the temporal lobe, especially in the primary cortex of hearing. Then the sounds will be processed and then sent to the Wernicke area to be interpreted. If you need a verbal response, then the interpretation is sent to Broca's area through archaic fasciculus. Unlike the input in the form of writing, the input is responded directly to the visual cortex in the osipital lobe. The input is not sent directly to the Wernicke area, but must pass through the angular gyrus. This angular movement coordinates areas of understanding with the osipital region. In addition, the brain has a part that handles intellectual functions and language called the cerebral cortex. In the human cerebral cortex there are left and right hemispheres. Left
\end{abstract}


hemisphere is responsible for linguistic matters. For that, if there is a disruption in the left hemisphere automatically, the language's speech ability decreases dramatically. Right hemisphere is more dominant in handling tasks related to design and visual patterns. The right hemisphere also affects a person's language, but not as much as the left hemisphere. If the right hemisphere is disturbed, then their ability to sort the events of a story (narrative) becomes chaotic and has difficulty attracting inference.

Keywords: brain, language, temporal lobe, prix cortex, broca, archic fasciculus, and osipital lobe

\section{PENDAHULUAN}

Dalam otak manusia ada struktur dan organisasinya yang memegang peranan penting dalam bahasa. Otak manusia nampak dari luar seperti sarung tinju (Donal J. Foss dan David T. Hakes, 1978:350). Otak seperti halnya tubuh dalam hal pembagian, ada belahan di tengahnya untuk memisahkan antara bagian kanan dan kiri. Di bagian tengah disebut motor cortex. Motor cortex berada di dekat daerah Broca agak ke belakang. Korteks ini bertugas untuk mengendalikan alat-alat ujaran seperti lidah, rahang, bibir, gigi, dan pita suara. Motor cortex akan menjalankan sesuai apa yang diperintahkan oleh Broca.

Kemampuan berbahasa manusia yang paling mendominasi terletak pada hemisfir kiri. Dengan alasan hemisfir kiri yang bertanggung jawab penuh atas kebahasaan (Soenjono Dardjowidjojo, 2012:2014). Telah banyak dibuktikan oleh para peneliti secara keseluruhan menunjukkan hasil yang sama bahwa jika hemisfir kiri yang dinon-aktifkan, maka gangguan wicaranya akan terganggu atau bahkan menurun drastis.

Selain hemisfir kiri, ada hemisfir kanan pada belahan otak yang lain. Hemisfir kanan juga dapat memengaruhi kebahasaan seseorang, namun tidak seintensif hemisfir kiri. Hal itu terbukti dengan adanya kasus-kasus pada umur belasan ke bawah, anak yang cedera hamisfir kirinya dapat memperoleh bahasa seperti anak normal. Hal itu menunjukkan bahwa hemisfir kanan pun mampu untuk melakukan fungsi kebahasaan. Akan tetapi di sini hemisfir kanan lebih berperan dalam kemampuan mengurutkan peristiwa sebuah cerita, kemampuan dalam menarik inferensi, kemampuan mendeteksi kalimat ambigu, dan kemampuan memahami metafora maupun sarkasme. 
Melalui kajian ini, akan diuraikan belahan otak mana yang memengaruhi berbahasa seseorang?, kapankah seseorang dikatakan sebagai manusia yang mengalami gangguan wicara?, dan apa akibat yang ditimbulkan jika seseorang mengalami gangguan wicara? Hal-hal itulah yang akan digali pada penelitian ini.

\section{METODE PENELITIAN}

Penulisan artikel ilmiah harus dilakukan penyusunan yang sistematis untuk memudahkan pemahaman pembaca. Untuk itu, Artikel ini menggunakan teknik studi literatur atau kajian pustaka. Berbagai buku, jurnal, dan laporan penelitian yang berkaitan dengan kajian psikolinguistik ini, khususnya tentang "hubungan operasionlitas bahasa dan otak manusia". Teknik ini bertujuan untuk mengungkapkan berbagai teori-teori yang relevan dengan permasalahan yang sedang diteliti sebagai bahan rujukan dalam pembahasan hasil penelitian. Informasi-informasi penting yang ditemukan dalam sumber, dicatat dan diolah guna manjawab topik pembahasan, sehingga menghasilkan tulisan yang utuh dan sistematis.

Pemilihan sumber referensi menjadi langkah awal, supaya tendensi yang dipakai dapat dipertanggungjawabkan kebenarannya (bersifat ilmiah). Analisis yang tajam dan kritis dapat membantu penyajian data yang komprehensif. langkah selanjutnya yakni mengolah informasi menjadi kalimat-kalimat yang penempatanya sesuai sub-sub bahasan.

\section{PEMBAHASAN}

\section{Perbedaan Otak Manusia dengan Hewan}

Secara fisik atau bentuk antara manusia dan hewan memang berbeda. Perbedaan itu terletak pada otaknya. Dibandingkan dengan hewan yang berukuran kecil ataupun besar tetap saja hanya manusia yang berbahasa. Bahkan manusia nanocephalic (manusia kate) yang otaknya hanya sekitar 400 gram (kira-kira sama dengan berat otak kera simpanse umur tiga tahun), manusia ini dapat berbicara secara normal sedangkan simpanse tidak (Tarigan, 1988:72). Hal ini menunjukkan bahwa hanya manusia yang dapat berbahasa atau menghasilkan tuturan (Nababan, 1992:17). Adapun ukuran berat otak manusia adalah antara 1 sampai $1.35 \mathrm{~kg}$ dengan rata-rata 1330 gram. Ukuran otak meskipun sekecil ini menyedot $15 \%$ dari seluruh peredaran 
darah dan memerlukan 20\% dari sumber daya metabolik manusia (Donal J. Foss dan David T. Hakes, 1978:354). Dari data yang ada, dijelaskan bahwa otak manusia memerlukan perhatian khusus dari badan kita.

Sistem saraf manusia terdiri atas dua bagian tulang punggung dan otak. Tulang punggung terdiri atas sederetan tulang punggung yang bersambungsambungan (spinalcord). Otak sendiri juga terdiri atas dua bagian batang otak (brain stem) dan korteks serebral (cerebral cortex). Tulang punggung dan korteks serebral ini merupakan sistem syaraf yang sentral bagi manusia. Segala bentuk kegiatan manusia, baik fisik atau mental dikendalikan oleh sistem syaraf ini. Dalam otak bagian pertama ada batang otak, terdiri atas medulla, pons, otak tengah, dan cerebellum. Bagian-bagian itu berkaitan dengan fungsi fisikal tubuh termasuk pernafasan, detak jantung, gerakan, refleks, pencernaan, dan pemunculan emosi. Bagian kedua berupa korteks serebral menangani masalah fungsi-fungsi intelektual dan bahasa.

Korteks serebral manusia terbagi atas hemisfir kiri dan hemisfir kanan. Kedua hemisfir ini dihubungkan oleh \pm 200 juta fiber yang dinamakan korpus kolosum. Hemisfir kiri mengendalikan semua anggota badan bagian kanan, termasuk muka bagian kanan. Sebaliknya, hemisfir kanan mengendalikan anggota badan dan muka bagian kiri. Peran korpus kolosum di sini mengintegrasi dan mengkoordinir kedua hemisfir di atas. Hemisfir kiri bertanggugjawab tentang ihwal kebahasaan. Untuk itu jika terjadi gangguan pada hemisfir kiri secara otomatis kemampuan wicara berbahasa orang itu menurun dengan drastis. Hemisfir kanan juga memengaruhi kebahasaan seseorang, namun tidak sebesar hemisfir kiri. Jika hemisfir kanannya yang terganggu, maka kemampuan mereka dalam mengurutkan peristiwa sebuah cerita (narasi) menjadi kacau dan mendapatkan kesukaran menarik inferensi.

Manusia memiliki proses produksi bahasa, semua terbagi menjadi tiga bagian otak yang berperan penting, yaitu daerah Wernick yang bertanggung jawab pada “lexical meaning”atau makna arti. Kedua, daerah Broca bertanggung jawab pada "grammatical planning" atau perencanaan tata. Ketiga, daerah Motor Suplementer (supplementary motor area) yang bertanggung jawab "monitoring” atau mengawasi dan mengendalikan hasil ucapan (Suherman, 2005:259). 
Ilustrasi atas ketiga daerah bagian otak di atas, dapat disimpulkan sebagai berikut tugas ketiga daerah itu, alur penerimaan dan penghasilan balasan ujaran (ucapan) dapat disederhanakan sebagai berikut: ujaran didengar dan dipahami melalui daerah Wernick, kemudian isyarat ujaran itu dipindahkan ke daerah Broca untuk mempersiapkan penghasilan balasan ujaran itu. Selanjutnya sebuah isyarat tanggapan ujaran itu dikirim ke daerah motor untuk menghasilkan ujaran secara fisik. Tentunya penyederhanaan itu mengabaikan penyebutan hubungan rumit system saraf dalam memasok darah ke otak dan sifat keterkaitan fungsi-fungsi otak.

Takala manusia dilahirkan usia 0-11 tahun belum ada pembagian tugas kedua hemisfir di aatas. Setelah usia 12 tahun baru ada pembagian tugas yang dinamakan lateralisasi (Soenjono Dardjowidjojo, 2012:205). Ada daerah yang dinamakan Wernicke. Wernicke hemisfir kiri lebih luas daripada bagian yang dimiliki hemisfir kanan. Hemisfir kiri terdiri atas empat daerah besar yang dinamakan lobe, yakni Lobe frontal, lobe temporal, lobe osipital, dan lobe parietal. Keempat lobe ini masingmasing memiliki tugas. Lobe frontal bertugas mengurusi ihwal yang berkaitan dengan kognisi. Lobe temporal bertugas mengurusi hal-hal yang berkaitan dengan pendengaran. Lobe osipital bertugas mengurusi hal-hal yang berkaitan dengan penglihatan. Lobe parietal bertugas mengurusi hal-hal yang berkaitan dengan rasa somaestetik (rasa yang ada pada tangan, kaki, muka, dan anggota badan yang lainnya).

\section{Penyebab Gangguan Wicara}

Gangguan wicara terjadi dikarenakan adanya kerusakan pada otak. Kerusakan otak dapat disebabkan oleh aliran darah pada otak tidak cukup, atau ada penyempitan pembuluh darah, atau gangguan lain yang menyebabkan jumlah oksigen yang diperlukan berkurang. Hal ini dapat mengakibatkan timbulnya sebuah penyakit. Penyakit semacam ini dinamakan stroke.

Penyakit stroke ini dapat berakibat pada otak. Dikarenakan adanya kontrol silang dari hemisfir kiri dan hemisfir kanan, maka stroke yang terdapat pada hemisfir kiri akan menyebabkan gangguan pada belahan badan sebelah kanan. Begitu juga sebaliknya, kalau strokenya terjadi pada hemisfir kanan, maka tubuh bagian kirilah yang akan terganggu. Kadar ketinggian stroke juga ditentukan oleh letak kerusakan 
pada hemisfir yang bersangkutan. Umumnya jika kerusakannya pada hemisfir kiri akan mengakibatkan gangguan wicara. Gangguan wicara yang disebabkan oleh stroke ini dinamakan afasia (aphasia).

Afasia sendiri dibagi menjadi lima, afasia Broca, afasia Wernicke, afasia anomik, afasia global, dan afasia konduksi. Pertama, afasia Broca adanya kerusakan pada daerah Broca. Daerah Broca ini berdekatan dengan jalur korteks motor, sehingga mengakibatkan alat-alat ujaran termasuk mulut akan terganggu. Bahkan mulut bisa mencong. Afasia Broca ini menyebabkan gangguan pada perencanaan dan pengungkapan ujaran. Untuk itulah kalimat-kalimat yang diproduksi terpatah-patah atau lafalnya tidak jelas.

Kedua afasia Wernicke, kerusakannya terletak pada daerah Wernicke, yakni bagian agak ke belakang dari lobe temporal. Korteks-korteks lain yang berdekatan bisa terkena juga. Penderita afasia Wernicke ini lancar dalam berbicara, dan bentuk sintaksisnya juga cukup baik. Hanya saja kalimat-kalimatnya sukar dimengerti, karena banyak kata yang tidak cocok maknanya dengan kata-kata sebelum dan sesudahnya. Selain itu, penderita afasia Wenricke ini juga mengalami gangguan dalam komprehensi lisan dan juga mengalami kesulitan dalam memahami apa yang orang lain katakan.

Afasia Anomik menjadi bagian ketiga. Afasia ini disebabkan oleh adanya kerusakan otak terjadi pada bagian depan dari lobe parietal atau pada batas antara lobe parietal dengan lobe temporal. Afasia ini gangguan wicaranya tampak pada ketidakmampuan dalam mengaitkan konsep dan bunyi atau kata yang mewakilinya.

Keempat afasia global. Afasia ini disebabkan karena terjadi kerusakan tidak hanya pada satu atau dua daerah saja tetapi di beberapa daerah yang lain. Kerusakan ini dapat menyebar dari daerah Broca, melewati korteks motor, menuju ke lobe parietal dan sampai ke daerah Wernicke. Luka yang sangat luas ini mengakibatkan gangguan fisikal dan verbal yang sangat besar. Dari segi fisik, penderita bisa lumpuh di bagian kanannya, mulut mencong, dan lidah bisa menjadi tidak fleksibel. Dari segi verbal, penderita bisa kesukaran dalam memahami ujaran orang, dan ketika berkatakata juga tidak cukup jelas.

Terakhir afasia konduksi, terjadi kerusakan pada bagian fiber-fiber yang ada pada fasikulus arkuat yang menghubungkan lobe frontal dengan lobe temporal. 
Karena hubungan daerah Broca di lobe frontal yang menangani produksi dengan daerah Wernicke di lobe temporal yag menangani komprehensi terputus, maka pendertia afasia konduksi ini tidak dapat mengulang kata yang baru saja diberikan padanya.

\section{Perbedaan Otak Wanita dengan Otak Pria}

Mengenai otak dibedakan pula otak pria dengan otak wanita. Dari segi bentuknya, hamisfir kiri pada wanita lebih tebal dari pada hemisfir kanan. Karena hal inilah yang menyebebkan kelas bahasa pada umumnya didominasi oleh wanita.

Otak wanita dan pria ketika sama-sama terserang afasia ada kecenderungan bahwa wanita berpeluang lebih besar untuk sembuh dibanding pria. Begitu halnya, saat terkena stroke, afasia lebih banyak muncul pada pria daripada wanita.

Selanjutnya orang yang tidak dapat berkomunikasi melalui lisan, mereka dapat menggunakan bahasa sinyal (sign languange). Bahasa sinyal ini menggunakan tangan dan jari-jari untuk membentuk kata dan kalimat. Bahasa sinyal ini tepatnya digunakan oleh orang tuna rungu. Bahasa ini ada berbagai macam, misalnya Bahasa Sinyal Amerika dan Bahasa Sinyal Inggris (Soenjono Dardjowidjojo, 2012:207).

Akan tetapi orang yang tuna rungu hemisfir kirinya kena stroke ternyata juga mengalami gangguan bahasa sama seperti yang dialami oleh penderita afasia Broka atau Wernicke manusia normal. Manusia yang menderita afasia Broca akan kesulitan dalam mensinyalkan apa yang ingin dinyatakan. Mungkin bisa dalam mensinyalkan kata, tetapi untuk gramatikalnya kacau.

Begitu juga bagi orang tuna rungu yang daerah Wernickenya terserang, mereka dapat memberikan sinyal dengan lancar tetapi maknanya tidak karuan. Gerakan tangan atau jarinya menghasilkan kata-kata namun tidak selaras dengan maknanya. Fakta lain menunjukkan untuk pengguna bahasa sinyal yang mengalami kerusakan hemisfir kanannya, ia tidak ada gangguan dalam bersinyal. Bentuk tata bahasanya masih utuh dan tidak terbata-bata.

\section{Pembuktian Hemisfir Kiri Dapat Terjadi Gangguan Wicara}

Untuk menjawab benar atau tidaknya gangguan wicara terjadi manakala hemisfir kiri seseorang bermasalah, maka hal ini perlu dibuktikan. Berdasar pada 
penelitian yang dilakukan pakar psikolog dengan cara memasukkan cairan ke kedua hemisfir, bila hemisfir kiri yang ditidurkan maka terjadilah gangguan wicara (Mar'at, 2005:86). Penelitian lain juga dilakukan oleh Kimura (1961) melakukan tes yang dinamakan dichotic listening test. Tes ini menunjukkan hasil yang sama. Kimura memberikan input pada telinga kiri dan kanan secara bersamaan. Bunyi da pada telinga kiri dan bunyi $b a$ pada telinga kanan. Alhasil input yang masuk melalui telinga kanan jauh lebih akurat daripada yang masuk lewat telinga kiri.

Manusia memiliki struktur dan organisasi otak yang sangat berperan dalam berbahasa. Pertama, Ketika input yang masuk berupa lisan, maka bunyi-bunyi itu akan ditanggapi oleh lobe temporal, khususnya korteks primer pendengaran. Di korteks inilah bunyi-bunyi tadi diolah seraca rinci, misalnya mendeteksi bunyi huruf apa yang didengar. Pendengaran dikatakan normal apabila memilki VOT+30 milidetik atau lebih. Bila VOT di bawah 30 milidetik, maka tidak dapat memilah bunyi yang masuk, dan akan menimbulkan vios, misalnya bunyi /b/ dengan /g/. Pada korteks ini pula akan memiliki bagaimana urutan bunyi yang masuk.

Langkah kerja otak selanjutnya, setelah bunyi tadi diterima, dicerna dan diolah, maka bunyi tersebut dikirim ke daerah Wernicke untuk di interpretasikan. Di daerah ini bunyi dipilah menadi sukukata, kata, frasa, klausa, atau kalimat. Setelah diberi makna dan difahami isinya, maka ada dua hal pilihan dalam melakukannya. Bila bunyi tadi hanya bersifat diterima saja, maka masukan tadi cukup disimpan di dalam memori. Namun, bila masukan tadi memerlukan tanggapan secara verbal, maka interpretasi itu dikirim di daerah Broca melalui fasikulus arkuat. Selanjutnya, di daerah Broca inilah proses dimulai. Setalah Broca memutuskan bunyi apa yang akan dikatakan, maka daerah Broca memerintahkan motor korteks untuk melaksanakannya. Tidak cukup sampai di sini, di motor korteks tidaklah sederhana, dalam menghasilkan suatu ujaran diperlukan minimal 100 otot dan 140.000 rentetan neuromuskoler yang terlibat. Selain itu, motor korteks juga mempertimbangkan tidak hanya urutan bunyi dan kata, tetapi juga urutan dari fitur-fitur pada tiap bunyi yang harus diujarkan. Untuk mengucapkan huruf /d/ motor korteks harus memerintahkan pita suara untuk bergetar 30 milidetik. Untuk bunyi /p/ pita suara harus diperintahkan untuk bergetar paling awal 25 milidetik setelah bunyi /p/diucapkan, hal ini bertujuan 
agar bunyi bilabial itu yang keluar benar-benar bunyi /p/ bukan bunyi /b/ (Soenjono Dardjowidjojo, 2012:210).

Kedua bila input yang masuk dalam bentuk tulisan, maka jalur pemrosesanya sedikit berbeda. Masukan tidak ditanggapi oleh korteks primer pendengaran, melainkan korteks visual (lobe osipital). Lobe opisital inilah yang menangani masalah penglihatan. Masukan itu tidak langsung dikirim ke daerah Wernicke, akan tetapi harus melewati girus angular terlebih dahulu untuk mengkoordinasikan daerah pemahaman dengan daerah osipital. Tahap selanjutnya sama dengan tahap masukan lisan, yakni input tadi dipahami oleh daerah Wernicke, lalu bila memerlukan tanggapan verbal dikirimlah ke daerah Broca. Namun, jika tanggapan juga berupa visual, maka informasi itu dikirim ke daerah parietal untuk diproses visualisasinya.

Fakta lain yang menunjukkan hemisfir kiri menguasai kerja anggota tubuh sebelah kanan, dan hemisfer kanan menguasai kerja anggota tubuh sebelah kiri. Tes dilakukandengan memperdengarkan pasangan kata yang berbeda, kata boy dan girl. Kedua kata ini dibisikkan ke telinga secara bersamaan dan juga kesamaan volume. Kata girl ke telinga kiri dan kata boy di telinga kanan. Ternyata kata boy yang diperdengarkan pada telinga sebelah kanan dapat diulangi dengan baik daripada kata girl yang diperdengarkan di telinga sebelah kiri.

Tes yang sama dilakukan pada anak-anak dan orang dewasa dengan bisikan pasangan kata-kata yang berbeda (Abdul Chaer, 2003:256). Ternyata hasilnya sama, kata yang diperdengarkan telinga sebelah kanan dapat diulang dengan baik, sedangkan kata yang diperdengarkan di telinga kiri tidak dapat mengulang dengan baik atas apa yang diperdengarkan.

\section{PENUTUP}

Berkaca pada uraian-uraian di atas, dapat disimpulkan bahwa untuk manusia, baik yang normal maupun yang cacat pendengaran (tuna rungu) jika mengalami kerusakan pada hemisfir kiri tentulah mengalami gangguan wicara. Berbeda dengan hemisfir kanan yang terganggu, mereka tetap dapat berbahasa, meskipun menemui kesulitan dalam mengurutkan sebuah cerita dan menarik inferensi.

Akibat yang ditimbulkan dari kerusakan otak adalah penyakit stroke. Bila penderita stroke yang terserang adalah hemisfir kirinya maka akan mengalami 
gangguan wicara, ini dinamakan afasia. Hal sama juga terjadi pada tuna rungu. Mereka yang hemisfir kirinya kena stroke juga akan mengalami gangguan dalam berbahasa.

\section{DAFTAR RUJUKAN}

Chaer, Abdul. 2003. Psikolinguistik: Kajian Teoretik. Jakarta: Rineka Cipta.

Dardjowidjojo, Soenjono. 2012. Psikolinguistik: Pengantar Pemahaman Bahasa Manusia. Jakarta: Yayasan Pustaka Obor Indonesia.

Harras, Kholid A. dan Bachari, Andika Dutha. 2009. Dasar-dasar Psikolinguistik. Bandung: UPI Press.

Foss, Donald J. dan David T. Hakes. 1978. Psycholinguistics: An Introduction To The Psychology of Languange. Amerika: Prentice Hall.

Suherman, A. 2005. Psicholinguistik. Bandung: Program Pendidikan Bahasa Arab FPBS UPI.

Mar'at, S. (2005). Psikolinguistik; Suatu Pengantar. Bandung: PT. Refika Aditama.

Nababan, SU. (1992). Psikolinguistik. Jakarta: Gramedia Pustaka Utama.

Tarigan, Guntur H .1988. Pengajaran Pemerolehan Bahasa. Jakarta: Depdikbud.

Mussofa. 2019. Menengok Bahasan Psikolinguistik [Online]. Tersedia http://massofa.wordpress.com/2008/01/24/menengokbahasanpsikolinguistik, diakses pada 29 Juni 2019, pukul 10.43 WIB.

Nurdirudiana, dan Agus. 2009. Psikolinguistik [Online] Tersedia: http://agusnurdinrudiana.blogspot.com/2009/06/psikolinguistik-antoiriantos_13.html, diakses pada 29 Juni 2019, pukul 11.00 WIB. 